\title{
Determining estrogenic steroids in Taipei waters and removal in drinking water treatment using high-flow solid-phase extraction and liquid chromatography/tandem mass spectrometry
}

\author{
Chia-Yang Chen ${ }^{\mathrm{a}, *}$, Tzu-Yao Wen ${ }^{\mathrm{a}}$, Gen-Shuh Wang ${ }^{\mathrm{a}, \mathrm{b}}$, Hui-Wen Cheng ${ }^{\mathrm{a}}$, \\ Ying-Hsuan Lin ${ }^{\text {a }}$, Guang-Wen Lien ${ }^{\text {a }}$ \\ ${ }^{a}$ Institute of Environmental Health, College of Public Health, National Taiwan University, 17 Hsu-Chou Road, Taipei (10055), Taiwan \\ ${ }^{\mathrm{b}}$ Department of Public Health, College of Public Health, National Taiwan University, 17 Hsu-Chou Road, Taipei (10055), Taiwan
}

Received 31 August 2006; received in revised form 18 February 2007; accepted 25 February 2007

Available online 10 April 2007

\begin{abstract}
River water and wastewater treatment plant (WWTP) effluents from metropolitan Taipei, Taiwan were tested for the presence of the pollutants estrone $\left(\mathrm{E}_{1}\right)$, estriol $\left(\mathrm{E}_{3}\right), 17 \beta$-estradiol $\left(\mathrm{E}_{2}\right)$, and $17 \alpha$-ethinylestradiol $\left(\mathrm{EE}_{2}\right)$ using a new methodology that involves high-flow solid-phase extraction and liquid chromatography/tandem mass spectrometry. The method was also used to investigate the removal of the analytes by conventional drinking water treatment processes. Without adjusting the $\mathrm{pH}$, we extracted 1-L samples with PolarPlus $\mathrm{C}_{18}$ Speedisks under a flow rate exceeding $100 \mathrm{~mL} / \mathrm{min}$, in which six samples could be done simultaneously using an extraction station. The adsorbent was washed with $40 \%$ methanol $/ 60 \%$ water and then eluted by $50 \%$ methanol $/ 50 \%$ dichloromethane. The eluate was concentrated until almost dry and was reconstituted by $20 \mu \mathrm{L}$ of methanol. Quantitation was done by LC-MS/MS-negative electrospray ionization in the selected reaction monitoring mode with isotope-dilution techniques. The mobile phase was $10 \mathrm{mMN}$-methylmorpholine aqueous solution/acetonitrile with gradient elution. Mean recoveries of spiked Milli-Q water were $65-79 \%$ and precisions were within $2-$ $20 \%$ of the tested concentrations $(5.0-200 \mathrm{ng} / \mathrm{L})$. The method was validated with spiked upstream river water; precisions were most within $10 \%$ of the tested concentrations $(10-100 \mathrm{ng} / \mathrm{L}$ ) with most RSDs $<10 \%$. LODs of the environmental matrixes were $0.78-7.65 \mathrm{ng} /$ L. A pre-filtration step before solid-phase extraction may significantly influence the measurement of $\mathrm{E}_{1}$ and $\mathrm{EE}_{2}$ concentrations; disk overloading by water matrix may also impact analyte recoveries along with ion suppression. In the Taipei water study, the four steroid estrogens were detected in river samples (ca. $15 \mathrm{ng} / \mathrm{L}$ for $E_{2}$ and $E_{2}$ and 35- $45 \mathrm{ng} / \mathrm{L}$ for $E_{1}$ and $E_{3}$ ). Average levels of $19-26 \mathrm{ng} / \mathrm{L}$ for $E_{1}$, $\mathrm{E}_{2}$, and $\mathrm{EE}_{2}$ were detected in most wastewater effluents, while only a single effluent sample contained $\mathrm{E}_{3}$. The higher level in the river was likely caused by the discharge of untreated human and farming waste into the water. In the drinking water treatment simulations, coagulation removed $20-50 \%$ of the estrogens. An increased dose of aluminum sulfate did not improve the performance. Despite the reactive phenolic moiety in the analytes, the steroids were decreased only $20-44 \%$ of the initial concentrations in pre- or postchlorination. Rapid filtration, with crushed anthracite playing a major role, took out more than $84 \%$ of the estrogens. Except for $E_{3}$, the whole procedure successfully removed most of the estrogens even if the initial concentration reached levels as high as $500 \mathrm{ng} / \mathrm{L}$.

(C) 2007 Elsevier B.V. All rights reserved.
\end{abstract}

Keywords: Steroid estrogen; River water; Wastewater effluent; LC-MS/MS; Endocrine disruptors

\footnotetext{
* Corresponding author. Tel.: +8862 3322 8101; fax: +8862 23519557.

E-mail address: dbms@ntu.edu.tw (C.-Y. Chen).
} 


\section{Introduction}

Feminizing pollutants $17 \alpha$-ethinylestradiol $\left(\mathrm{EE}_{2}\right)$ from oral contraceptives, $17 \beta$-estradiol $\left(\mathrm{E}_{2}\right)$, as well as their metabolites estrone $\left(E_{1}\right)$ and estriol $\left(E_{3}\right)$ have been detected at $\mathrm{ng} / \mathrm{L}$ levels in natural water and wastewater treatment plants (WWTP) influents/effluents (Desbrow et al., 1998; Ying et al., 2002). Even at these low concentrations, these pollutants can adversely affect production of vitellogenin in male fish and the sex ratio of fish populations (Jobling et al., 1998; Vethaak et al., 2005). Glucuronides or sulfates of these chemicals can be deconjugated by microorganisms in WWTP or the environment, and form biologically-active parent compounds (Desbrow et al., 1998; Ternes et al., 1999).

The most extensively used method to detect trace amounts of estrogenic steroids in water is solid-phase extraction (SPE) coupled to GC-MS(/MS), and detection limits can reach below $1 \mathrm{ng} / \mathrm{L}$ (Quintana et al., 2004; Xiao et al., 2001). However, the chemical derivatization process needed to prepare the analytes for injection into $\mathrm{GC}$ is time-consuming and labor-intensive. Recently, solid-phase microextraction (SPME) with on-fiber derivatization has been reported to accelerate this process (Carpinteiro et al., 2004). Another analytical equipment, LC-MS/MS, is as sensitive as GC-MS and does not require as much pre-treatment (Benijts et al., 2004; Vanderford et al., 2003).

There are some problems involved in the detection of $E_{1}, E_{2}, E_{2}$, and $E_{3}$ in water. Due to the weak acidity of the four chemical pollutants, water samples need to be acidified for better retention of the analytes for reversedphase SPE (Isobe et al., 2003; Quintana et al., 2004). This acidification, however, may co-extract more humic or fulvic acids and interfere with the analysis. In addition, a disk-type adsorbent, which allows much faster flow than a cartridge, has obvious benefits when it is necessary to extract a large volume of water.

The possibility that particulates may bind fractions of these moderately hydrophobic chemicals has not been adequately studied in water treatment systems (Snyder et al., 2003; Ying et al., 2002). Moreover, to avoid blocking the adsorbent, the currently-used SPE procedure pre-filters water samples before extraction to eliminate particulates and may underestimate the total concentration of the estrogens.

There is little information about the removal of estrogenic steroids when treating drinking water. Because of the phenolic moieties of the estrogens, oxidation can reduce the estrogenic activities (Deborde et al., 2004; Westerhoff et al., 2005). They have been reported to react more rapidly with ozone than with chlorination (Alum et al., 2004; Zwiener and Richardson, 2005). On the contrary, Itoh et al. (2000) found a 2.3-fold increase in estrogenic effect in lake water after it was chlorinated. While estrogens have been removed efficiently by such advanced treatments as activated carbon, manganese oxide, and reverse osmosis (Westerhoff et al., 2005), it is not well established how efficiently they are removed by more conventional processes such as coagulation/sedimentation and filtration. Finally, some of the studies investigating the removal of estrogens from drinking water started with initial concentrations at tens of $\mu \mathrm{g} / \mathrm{L}$, concentrations much higher than usually found in the environment and may, therefore, not be relevant (Carlile et al., 1996; Lee et al., 2004).

In this paper, we report a faster and easier method for quantifying the low $\mathrm{E}_{1}, \mathrm{E}_{2}, \mathrm{EE}_{2}$, and $\mathrm{E}_{3}$ levels typically found in water samples using LC-MS/MS with isotopedilution techniques. Without adjusting the $\mathrm{pH}$, river water, WWTP effluents and treated drinking water were extracted by a disk-type adsorbent at a flow rate greater than $100 \mathrm{~mL} / \mathrm{min}$. We found the detection limits of this method for these three matrixes to be $0.8-7.7,1.3-7.2$ and $0.06-0.15 \mathrm{ng} / \mathrm{L}$, respectively. Pre-filtration of particulates before SPE might cause the underestimation of the total concentrations of $\mathrm{E}_{1}$ and $\mathrm{EE}_{2}$; disk overloading by the water matrix influenced the analyte recoveries in addition to ion suppression. We also investigated the removal of the analytes in drinking water treatment processes and found that rapid filtration eliminated much more analytes than other water treatment units, while both chlorination and coagulation/sedimentation removed between 20 and $40 \%$. Conventional drinking water treatment removed over $88 \%$ of $\mathrm{E}_{1}, \mathrm{E}_{2}$, and $\mathrm{EE}_{2}$, but less $\mathrm{E}_{3}$.

\section{Materials and methods}

\subsection{Chemicals}

Estrone, estriol, $17 \beta$-estradiol, and $17 \alpha$-ethinylestradiol were purchased from Sigma (Saint Louis, MO, USA; purity $>98 \%$ ). $3,4-{ }^{13} \mathrm{C}_{2}-17 \beta$-estradiol was obtained from Cambridge Isotope Laboratories (Andover, MA, USA; purity $99 \%$ ). $2,4,16,16-{ }^{2} \mathrm{D}_{4}$-estrone, $2,4,17-{ }^{2} \mathrm{D}_{3}$-estriol, and $2,4,16,16-{ }^{2} \mathrm{D}_{4}-17 \alpha$-ethinylestradiol were bought from $\mathrm{C} / \mathrm{D} / \mathrm{N}$ Isotope (Pointe-Claire, Quebec, Canada; purity 98\%). Solvents (HPLC grade) were purchased from J.T. Baker (Phillipsburg, NJ, USA). $N$-methylmorpholine was provided by Aldrich (Saint Louis, MO, USA; purity $>99.5 \%$ ). All standards were prepared in methanol and stored at $4{ }^{\circ} \mathrm{C}$. 


\subsection{Sample collection}

Grab samples from the Dan-Shui River, the major river flowing through Taipei City, were collected from

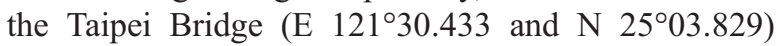
during June and September, 2004. Effluents of Nei-Hu WWTP in Taipei City (a secondary treatment facility with activated sludge units and a capacity of 240,000 CMD (cubic meter per day)) were collected during July and October, 2004. The samples had $\mathrm{pH}$ between 6.3 and 6.6 and temperature between 26 and $29^{\circ} \mathrm{C}$. Samples were sealed in 1-L pre-cleaned amber glass bottles with Teflon-liner caps and were stored at $4{ }^{\circ} \mathrm{C}$ until analysis; $1 \%$ formaldehyde was added as preservative (Fine et al., 2003; Petrovic and Barcelo, 2000). Twenty ng of each stable isotope-labeled internal standard (IS) were spiked into a 1-L sample, which was filtered using $90-\mathrm{mm}$ PVDF (polyvinylidene fluoride) filter (pore size $0.45 \mu \mathrm{m})$. The sample was shaken for $30 \mathrm{~min}$ at $130 \mathrm{rpm}$ before extraction.

Milli-Q water was used as a matrix for analytical method optimization. The raw water source of ChangHsing drinking water treatment plant (WTP) from SinDian Creek, which supplies drinking water for most of the population of Taipei City, was used as the matrix for method validation and for investigating the removal of estrogenic steroids from the water treatment processes. One-liter filtered samples were spiked with 100 or $500 \mathrm{ng}$ of native compounds and with $50 \mathrm{ng}$ of each IS; the samples were shaken as described above before following treatment. The raw water only contained trace levels of analytes that were relatively insignificant to the spiked amount. All the sampling sites are shown in Fig. 1.

\subsection{Simulation of drinking water treatments}

During the pre-chlorination, $1 \mathrm{~L}$ of spiked raw water (pH 7.2-7.6) was shaken with $1 \mathrm{mg} / \mathrm{L}$ sodium hypochlorite for $10 \mathrm{~min}$ at $110 \mathrm{rpm}$. The turbidities of samples after treatment were all lower than 10 NTU (measured by a Hach 2100P turbidimeter, Loveland, CO, USA). Coagulations were conducted as jar tests using a six-place gang stirrer (Fargo Model MS-121); $1 \mathrm{~L}$ of spiked raw water was subjected to $1 \mathrm{~min}$ of rapid mixing (100 rpm) with aluminum sulfate octadecahydrate (alum, $5 \mathrm{mg} / \mathrm{L}$ ), 30-min flocculation at $20 \mathrm{rpm}$, and 30 -min settling while the $\mathrm{pH}$ was controlled at 6.2-7.1. The supernatant was collected for analysis.

Rapid filtration simulated the design of Shui-An Rapid Sand Filter using a Wheeler filter bottom. A 150-

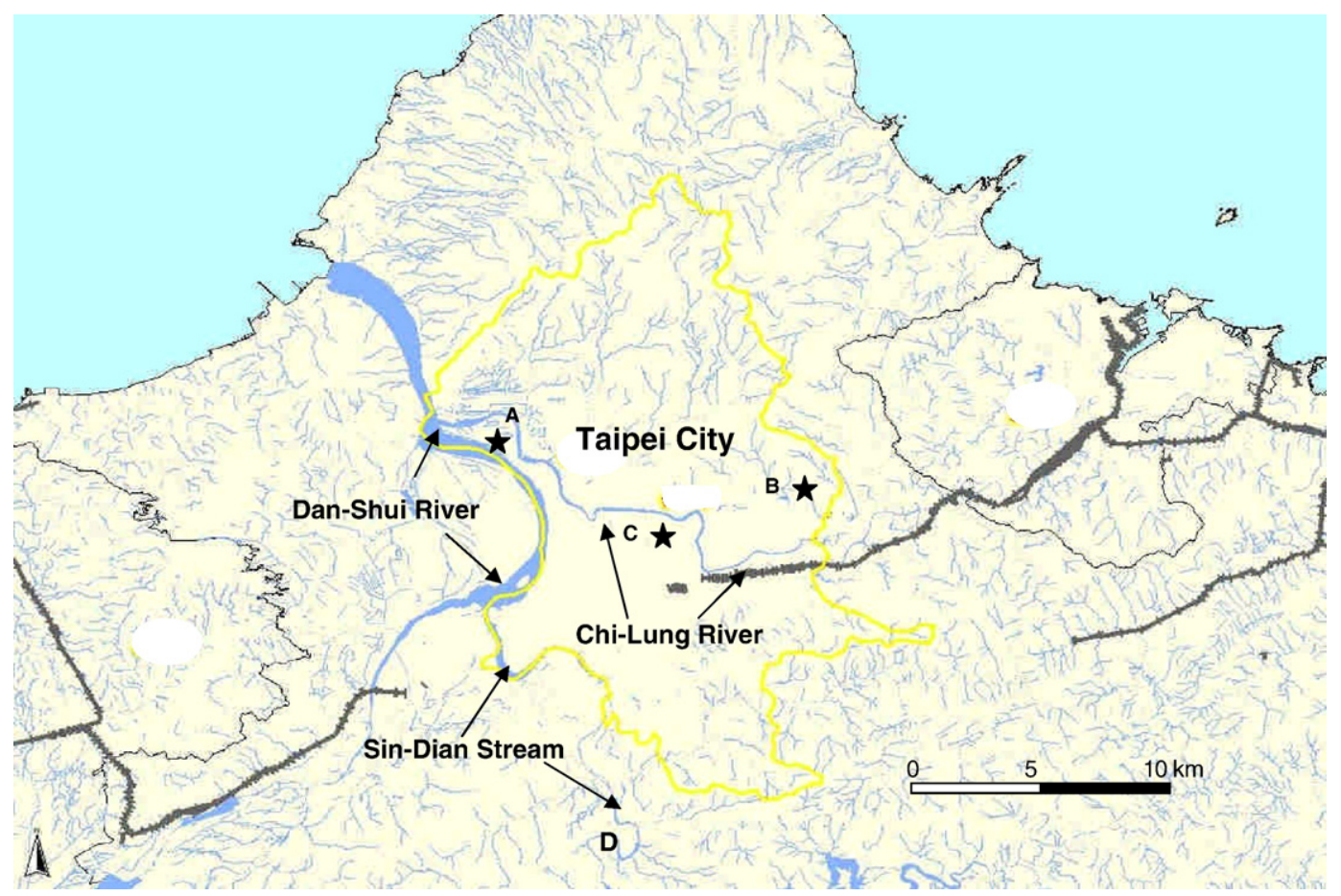

Fig. 1. Sampling locations of Taipei Bridge (A), Nei-Hu WWTP (B) and Chang-Hsing WTP (C). The black spot (D) is the intake for the WTP. The discharge of the WWTP enters the nearby Chi-Lung River. The yellow line indicates the area of the Taipei City. The map was modified from the web sites of Taiwan EPA (http://edb.epa.gov.tw/gis/func1/frame.asp and http://www.epa.gov.tw/attachment_file/). 
$\mathrm{cm}$ glass column (10-mm i.d.) was packed with $30-\mathrm{cm}$ filter gravel (grain size 2-50 mm), 51-cm filter sand (grain size $0.3-1.2 \mathrm{~mm}$ ) and $25-\mathrm{cm}$ crushed anthracite (grain size $0.6-2.4 \mathrm{~mm}$ ). The flow rate was controlled at $20 \mathrm{~mL} / \mathrm{min}$ (flow velocity $\approx 296 \mathrm{~m} /$ day) using a Masterflex HV-77601-00 I/P-tubing pump (Vernon
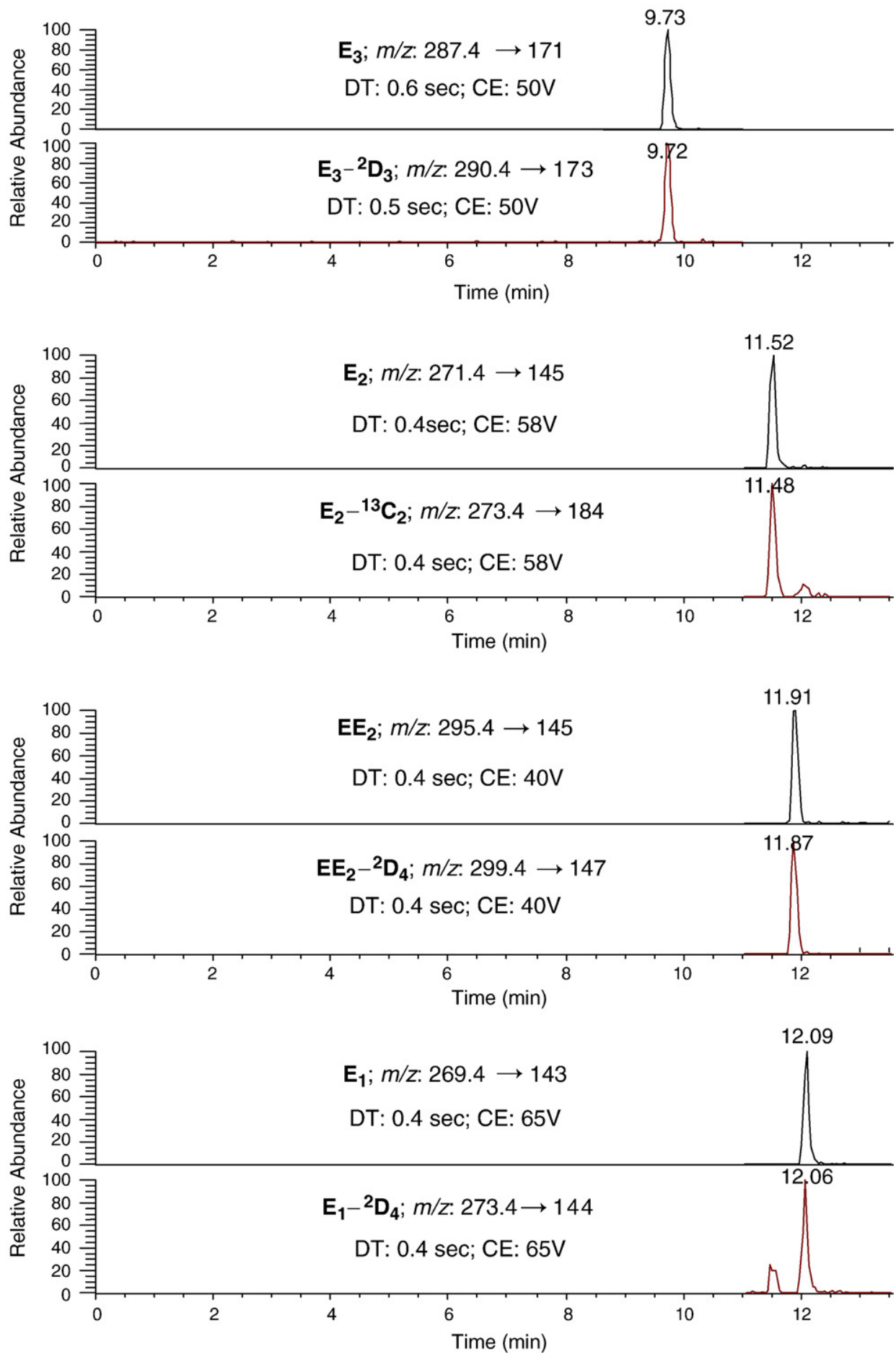

Fig. 2. The chromatogram of the analytes and their internal standards (SRM Mode; m/z: precursor ion $\rightarrow$ product ion; DT: dwelling time; CE: collision energy; injection $4-\mu \mathrm{L}$ standard of $10 \mathrm{ng} / \mu \mathrm{L} \mathrm{E}_{3}$ and $\mathrm{E}_{2}$ and $5 \mathrm{ng} / \mu \mathrm{L}$ of $\mathrm{E}_{1}$ and $\mathrm{EE}_{2}$ ). 
Hills, IL, USA). One liter of raw water was prechlorinated and coagulated, and then spiked and treated. Additional 15-mL Milli-Q water was used to flush the column and was collected together with the spiked sample for analyzing estrogens.

The post-chlorination procedure (at $\mathrm{pH} 6.8-7.1$ ) was similar to that of pre-chlorination; however, the raw water was treated through pre-chlorination, coagulation and rapid filtration before spiking the analytes. Free chlorine residuals were $0.5-0.7 \mathrm{ppm}$ (measured by a Hach pocket colorimeter) after the treatment. The entire experimental process treated 1-L spiked raw water through the four steps as described above.

\subsection{Extraction and analysis}

Samples were passed through 50-mm Bakerbond PolarPlus C18 Speedisks (J.T. Baker, Phillipsburg, NJ, USA, conditioned with $10 \mathrm{~mL}$ of $50 \%$ methanol $/ 50 \%$ dichloromethane (v:v), methanol, and Milli-Q water sequentially) at a flow rate of $110-130 \mathrm{~mL} / \mathrm{min}$. Six samples could be handled simultaneously using a Diskmate II rotary extraction station (J.T. Baker). After extraction, the sample reservoirs were rinsed with $20 \mathrm{~mL}$ of Milli-Q water; the disks were flushed with the rinsed water, followed by $10 \mathrm{~mL}$ of $40 \%$ methanol $/ 60 \%$ water (v:v). The disks were moved to a vacuum manifold (J.T. Baker) and dried for $10 \mathrm{~min}$ using a vacuum system (about- $25 \mathrm{kPa}$ ) before being eluted with three portions of $5-\mathrm{mL} 50 \%$ methanol $/ 50 \%$ dichloromethane. The collected eluate was filtered through $25 \mathrm{~mm}$ PTFE syringe filters (pore size 0.2$\mu \mathrm{m})$, combined with two rinses of $0.5-\mathrm{mL}$ methanol, and concentrated to barely dry at $45^{\circ} \mathrm{C}$ in a $1.8-\mathrm{mL}$ vial by a vacuum centrifuge (Thermo Savant SPD 1010 SpeedVac, Holbrook, NY, USA). Residues were reconstituted with $20 \mu \mathrm{L}$ of methanol and $4 \mu \mathrm{L}$ was injected.

A DU 2001 in-line solvent degasser (Sanwa Tsusho, Tokyo, Japan) and a Hitachi L-7100 HPLC pump (Tokyo, Japan) were coupled to a Thermo Finnigan TSQ 7000 triple-quadrupole mass spectrometer in negative electrospray ionization (ESI). The voltages of source, capillary, and tube lens were $4.51 \mathrm{kV},-52 \mathrm{~V}$ and $-143 \mathrm{~V}$, respectively. The capillary temperature was $250{ }^{\circ} \mathrm{C}$. A BetaBasic $\mathrm{C} 18$ column was used for HPLC $(150 \times 2.1 \mathrm{~mm}, 3 \mu \mathrm{m}$, Hypersil-Keystone, Bellefonte, PA, USA) and the temperature was kept at $60{ }^{\circ} \mathrm{C}$ using an ECO-1 column oven (Analab, Taipei, Taiwan). Eluent A was acetonitrile and eluent $\mathrm{B}$ was $10 \mathrm{mM}$ aqueous $N$-methylmorpholine in Milli-Q water ( $\mathrm{pH} 9.6$ ) at a flow rate of $0.2 \mathrm{~mL} / \mathrm{min}$. The elution started with $10 \%$ of eluent $\mathrm{A}$, followed by a 2 -min gradient to $60 \%$ of eluent A and a 10.5 -min gradient to $100 \%$ of eluent A and then kept $100 \%$ for one more minute.

Data were obtained by selected reaction monitoring (SRM). The collision gas was argon and the cell pressure was 3 mTorr. The electron multiplier voltage was $1740 \mathrm{~V}$. The sheath gas and auxiliary gas were nitrogen at 70 PSI and 20 PSI, respectively. There were two sections in a run: only the channels of $E_{3}$ and $\mathrm{E}_{3}-{ }^{2} \mathrm{D}_{3}$ were monitored at the first $11 \mathrm{~min}$ (one data point every $1.1 \mathrm{~s}$ ); the retention time of $\mathrm{E}_{2}, \mathrm{EE}_{2}$, and $\mathrm{E}_{1}$ was too close and had to be monitored together with their IS during the remaining $2.5 \mathrm{~min}(2.4 \mathrm{~s} /$ cycle $)$. With the dwelling time described in Fig. 2, we optimized both the intensity and stability of the signals.

\section{5. $Q A / Q C$, quantification, and data analysis}

All glassware was rinsed with acetone, hexane, dichloromethane and methanol after it was washed and before being used for experiments. A Milli-Q water sample and two duplicates of real samples spiked with IS were run with each batch of samples to check for experimental contamination and access method reproducibility (all agreed within 16\%). Isotope-dilution techniques were used to correct for variations in sample recovery and instrumental performance. Peak areas of analytes were normalized to those of their IS. Five specific concentrations of native analytes (ranging 0.05-5 ng/ $\mu \mathrm{L}$ for $\mathrm{E}_{1}$ and $\mathrm{EE}_{2}$ and $0.05-10 \mathrm{ng} / \mu \mathrm{L}$ for $E_{2}$ and $E_{3}$ ) with a fixed $1 \mathrm{ng} / \mu \mathrm{L}$ of their stable isotopelabeled chemicals in methanol were injected for each analysis to build up a calibration curve $\left(r^{2}\right.$ values were at least 0.98). Recoveries of the analytes and IS were calculated based on the standards added; therefore, both their losses in the sample preparation and matrix effects on the instrument influenced recoveries. LODs and LOQs were set at heights of threefold and tenfold over noise, respectively. Recovery differences of IS between spiking before and after filtration of water samples were compared with two-sample one-tailed Student's $t$-test. One-tailed $t$-test and One-Way ANOVA (Scheffe method) were used for comparing the removal percentage in different treatment processes.

\section{Results and discussion}

\subsection{Analytical method development and validation}

PolarPlus C18 adsorbent (14-18\% carbon content, not end-capped) was able to extract the four estrogenic steroids at a high-flow rate without acidifying water samples. It performed better than the usual C18 (10- 
Table 1

Quantification of the spiked Milli-Q water samples (1 L, $n=5$ )

\begin{tabular}{llll}
\hline Spiked level $(\mathrm{ng} / \mathrm{L})$ & 5.0 & 50 & $200^{\mathrm{a}}$ \\
\cline { 2 - 4 } Analyte & Measured concentration $(\mathrm{ng} / \mathrm{L})^{\mathrm{b}}$ & & \\
\hline $\mathrm{E}_{1}$ & $4.9 \pm 1.6(-1.4 \%)$ & $39.5 \pm 9.7(-21 \%)$ & $170 \pm 36(-15 \%)$ \\
$\mathrm{E}_{2}$ & $5.2 \pm 1.3(+3.2 \%)$ & $47.9 \pm 13(-4.2 \%)$ & $176 \pm 53(-12 \%)$ \\
$\mathrm{EE}_{2}$ & $5.9 \pm 0.2(+19 \%)$ & $46.3 \pm 6.3(-7.5 \%)$ & $195 \pm 38(-2.6 \%)$ \\
$\mathrm{E}_{3}$ & $6.0 \pm 1.2(+21 \%)$ & $52.8 \pm 9.8(+5.5 \%)$ & $233 \pm 12(+17 \%)$ \\
\hline a & $n=4$. & & \\
b $\quad$ Shown as mean $\pm \mathrm{SD}$ (relative deviation from the spiked level).
\end{tabular}

$14 \%$ carbon content). The C18 Speedisk cartridges $(50 \mathrm{mg}$ ) retained $88-93 \%$ of the four chemicals from $1 \mathrm{~mL}$ of $16 \mu \mathrm{g} / \mathrm{mL}$ Milli-Q water $(n=3)$, but PolarPlus C18 retained over $99 \%$ of each analyte. Moreover, no breakthrough was detected in 1-L samples using PolarPlus C18 50-mm disks containing up to $200 \mathrm{ng} / \mathrm{L}$ except for $\mathrm{E}_{1}(\approx 31 \%$ was not trapped at the last $300 \mathrm{~mL}$ of the samples). We further investigated various solvents or their combinations (Sole et al., 2000; Xiao et al., 2001) and the best eluting solution, $15 \mathrm{~mL}$ of $50 \%$ methanol $/ 50 \%$ dichloromethane, gave recoveries of $\mathrm{E}_{1}$, $\mathrm{E}_{2}, \mathrm{EE}_{2}$, and $\mathrm{E}_{3}$ at $95.0 \pm 10.4 \%, 90.2 \pm 6.9 \%, 87.7 \pm$ $15.8 \%$, and $95.1 \pm 11.9 \%$, respectively (mean $\pm \mathrm{SD}$, $n=3)$.

The washing process with $40 \%$ methanol $/ 60 \%$ water, a cleanup procedure followed by Xiao et al. (2001), did not significantly reduce the recovery. The loss of $\mathrm{E}_{1}, \mathrm{E}_{2}$, $\mathrm{EE}_{2}$ and $\mathrm{E}_{3}$ resulting from this step were 1.7-1.9\%, 0.9$1.2 \%, 1.4-1.6 \%$, and $2.4-3.4 \%$, respectively $(n=2)$.

The method recovery, accuracy, and linearity were demonstrated with replicates of spiked Milli-Q water. The recoveries of $\mathrm{E}_{1}, \mathrm{E}_{2}, \mathrm{EE}_{2}$, and $\mathrm{E}_{3}$ were $75.5 \pm$ $16.6 \%, 78.6 \pm 18.0 \%, 67.8 \pm 13.2 \%$, and $65.2 \pm 17.0 \%$, respectively (spiked at $20 \mathrm{ng} / \mathrm{L}$, mean $\pm \mathrm{SD}, n=6$ ). Average LODs of $\mathrm{E}_{1}, \mathrm{EE}_{2}$, and $\mathrm{E}_{3}$ were 0.16-0.24 ng/ $\mathrm{L}$ and their method detection limits at $99 \%$ confidence level (MDL $99 \%$ ) were $0.29-0.39 \mathrm{ng} / \mathrm{L}$, respectively; those of $E_{2}$ were higher $(0.48$ and $1.2 \mathrm{ng} / \mathrm{L}$, respectively). The discrepancies from three spiked concentrations $(5.0,50$, and $200 \mathrm{ng} / \mathrm{L}, n=5)$ were most within $15 \%$, which verified the accuracy and linearity of the method (Table 1).

The method was validated with the spiked samples of raw water from Sin-Dian Creek. Average LODs and LOQs of the four chemicals were $0.47-1.3 \mathrm{ng} / \mathrm{L}$ and 1.6-4.3 ng/L, respectively (Table 2). The reported values of the spiked samples did not deduct the endogenous amount of the analytes (ND-5.6 ng/L) in the raw water; therefore, at the lowest spiked level $(10 \mathrm{ng} / \mathrm{L})$, the measured concentrations were somewhat higher than the added amount, and the RSDs were up to $23 \%$. On the other hand, for the spiked samples at 50 and $100 \mathrm{ng} / \mathrm{L}$, the measured levels were comparable to the fortified amount with small variations (RSDs $\leq 7 \%$ ).

Addition of $N$-methylmorpholine to the mobile phase achieved a higher dissociation of the phenolic analytes $\left(\mathrm{p} K_{\mathrm{a}} \approx 10.4\right)$ and resulted in a stronger signal in ESI without influencing the chromatography. Literature also demonstrated that addition of a weak base directly or post-column to mobile phase can increase the ESI response of estrogenic phenolic chemicals (Baronti et al., 2000; Chen et al., 2001; Johnson et al., 2000). In a neutral solution, their dissociation fraction is only about $0.04 \%$; when the $\mathrm{pH}$ is elevated to $\mathrm{pH} 9.6$ in the $10-\mathrm{mM}$

Table 2

Quantification of the spiked samples of raw water from Sin-Dian Creek (1 L, $n=4)$

\begin{tabular}{|c|c|c|c|c|c|c|}
\hline Spiked level (ng/L) & No spike ${ }^{a}$ & 10 & 50 & 100 & $\begin{array}{l}\text { Mean } \\
\text { of LOD }\end{array}$ & $\begin{array}{l}\text { Mean } \\
\text { of LOQ }\end{array}$ \\
\hline Analyte & & Measured concentration (ng/L) ${ }^{b}$ & & & $(\mathrm{ng} / \mathrm{L})^{\mathrm{c}}$ & $(\mathrm{ng} / \mathrm{L})^{\mathrm{d}}$ \\
\hline$E_{1}$ & $4.18-5.57$ & $15.2 \pm 0.9(6.2 \%)$ & $59.2 \pm 1.4(2.4 \%)$ & $116 \pm 12(11 \%)$ & 0.47 & 1.57 \\
\hline $\mathrm{E}_{2}$ & ND-2.85 & $13.2 \pm 3.1(23 \%)$ & $49.5 \pm 2.9(5.8 \%)$ & $99.2 \pm 1.6(1.7 \%)$ & 0.80 & 2.67 \\
\hline $\mathrm{EE}_{2}$ & ND & $13.1 \pm 0.5(3.4 \%)$ & $47.6 \pm 3.4(7.1 \%)$ & $98.3 \pm 6.7(6.8 \%)$ & 0.55 & 1.83 \\
\hline $\mathrm{E}_{3}$ & $\mathrm{ND}-5.20$ & $17.9 \pm 4.1(23 \%)$ & $47.1 \pm 2.6(5.5 \%)$ & $95.2 \pm 5.7(5.9 \%)$ & 1.29 & 4.30 \\
\hline
\end{tabular}

\footnotetext{
$n=3 ; \mathrm{ND}:<\mathrm{LOD}$.

Shown as mean $\pm \mathrm{SD}$ (RSD).

LOD: $\mathrm{S} / \mathrm{N} \geq 3$.

d LOQ: $\mathrm{S} / \mathrm{N} \geq 10$.
} 
Table 3

Concentrations in river water and WWTP effluents (ng/L, $n=10)^{\mathrm{a}}$

\begin{tabular}{|c|c|c|c|c|c|c|c|c|}
\hline Matrix & Analyte & Recovery of IS (\%) & Mean of LOD & $n>\mathrm{LOD}^{\mathrm{b}}$ & Min & Max & Median & Mean \\
\hline \multirow[t]{4}{*}{ River water } & $\mathrm{E}_{1}$ & $35.7 \pm 6.1$ & 0.78 & 10 & 22.4 & 66.2 & 31.1 & 34.7 \\
\hline & $\mathrm{E}_{2}$ & $23.7 \pm 12.4$ & 3.11 & 10 & 1.40 & 33.9 & 14.5 & 14.4 \\
\hline & $\mathrm{EE}_{2}$ & $25.0 \pm 8.8$ & 1.16 & 8 & 7.53 & 27.4 & 14.1 & 15.3 \\
\hline & $\mathrm{E}_{3}$ & $9.64 \pm 6.03$ & 7.65 & 10 & 12.4 & 73.6 & 58.1 & 44.5 \\
\hline \multirow[t]{4}{*}{ WWTP effluents } & $\mathrm{E}_{1}$ & $53.1 \pm 22.7$ & 1.31 & 10 & 10.2 & 48.6 & 22.7 & 26.0 \\
\hline & $\mathrm{E}_{2}$ & $21.6 \pm 10.6$ & 7.22 & 8 & 4.50 & 44.5 & 17.8 & 23.0 \\
\hline & $\mathrm{EE}_{2}$ & $36.9 \pm 12.2$ & 1.80 & 10 & 2.25 & 37.9 & 17.1 & 19.0 \\
\hline & $\mathrm{E}_{3}$ & $16.3 \pm 9.8$ & 5.86 & 1 & - & 39.1 & - & - \\
\hline
\end{tabular}

a Samples were filtered prior to extraction.

b Number in the ten samples that were detectable $(S / N \geq 3)$. Statistical data shown were calculated based on detectable samples.

$\mathrm{N}$-methylmorpholine(aq), the dissociation fraction is raised to $13.7 \%$ and the signals were enhanced a lot. The authors tried a more basic ammonium hydroxide $(\mathrm{aq})$ at $10 \mathrm{mM}$ (pH 10.8); the peaks showed significant tailing, which may indicated less retention because of a higher dissociation.

\subsection{Environmental water samples}

\subsubsection{Analysis of real samples}

The levels of steroid estrogens in the Dan-Shui River (Table 3) were higher than most other reports on surface water (Adler et al., 2001; Mouatassim-Souali et al., 2003; Xiao et al., 2001); however, these previous investigations, which have ranged from $<$ LOD to low ng/L levels, were from Japan and European countries, where most sewage is treated before discharge. We detected $\mathrm{E}_{2}$ and $\mathrm{EE}_{2} \approx 15 \mathrm{ng} /$ $\mathrm{L}$ on an average in the river water; $\mathrm{E}_{1}$ and $\mathrm{E}_{3}$ were in the range of 35-45 ng/L. The chromatograms of real samples (Figs. 3 and 4) indicated that background noise may interfere with the quantification at levels below $10 \mathrm{ng} / \mathrm{L}$; however, this does not necessarily comprise the data reported because the concentrations observed were most significantly above $10 \mathrm{ng} / \mathrm{L}$. The Dan-Shui River has been classified as seriously polluted by the Taiwan EPA (2006). About $47 \%$ of the total discharge from the basin is untreated domestic sewage and livestock-breeding wastewater, though amounts are decreasing; if based on $\mathrm{NH}_{3}-$ $\mathrm{N}$ measurements, the contribution of these two categories is around $79 \%$. The DO, BOD, $\mathrm{COD}, \mathrm{NH}_{3}-\mathrm{N}$, and total phosphorus during our sampling were $0.5-0.8,2.9-9.0$, 20.4-24.2, 2.81-4.96, and $0.471-0.534 \mathrm{mg} / \mathrm{L}$, respectively (TDEP (Taipei Department of Environmental Protection), 2004), which indicated poor water quality. Since Taipei is the most crowded area in Taiwan (9649 persons $/ \mathrm{km}^{2}$ in Taipei vs the average number 627 in Taiwan at the end of year 2004, based on the National Statistics of Taiwan), it was not surprising to discover a higher concentration of these chemicals from our sampling location. A USGS study (Kolpin et al., 2002a) reveals higher levels of estrogenic steroids in streams relative to most reports because they targeted sites susceptible to contamination from human, industrial, and agricultural wastewater, although the data in that study were criticized because GC/MS detection is subject to artifacts from organic matter (Ericson et al., 2002; Kolpin et al., 2002b). Kolodziej et al. (2004) also demonstrated that sources other than municipal wastewater (such as farming wastes) can contribute the level of steroid hormones in surface waters.

Previous studies indicate that $\mathrm{EE}_{2}$ emissions are usually lower than one-tenth of $\mathrm{E}_{2}$, but can reach equal levels in water because of persistence (Jurgens et al., 1999; Spengler et al., 2001), which is consistent with our results. We also found higher concentrations of $E_{1}$ and $E_{3}$ than $E_{2}$ and $\mathrm{EE}_{2}$ in the river water, and this agrees with previous reports (Baronti et al., 2000; Xiao et al., 2001). $E_{1}$ is one of the major metabolites of $\mathrm{E}_{2}$ and $\mathrm{EE}_{2}$; it degrades slowly in the environment mainly into $\mathrm{E}_{3}$ (Arcand-Hoy et al., 1998). Adlercreutz et al. (1994) also reported that daily urine excretions of $E_{1}, E_{2}$, and $E_{3}$ in oriental pre-menopausal women were $2.66,1.09$, and $5.68 \mu \mathrm{g}$. These would explain the higher levels of $E_{1}$ and $E_{3}$.

Concentrations of $E_{1}, E_{2}$, and $E_{2}$ in WWTP effluents have varied significantly in previous investigations, which were influenced by operational conditions of WWTP, climates, and composition of influents. The medians of $\mathrm{E}_{1}$, $E_{2}$, and $E_{2}$ in the effluents in our investigation were 17$23 \mathrm{ng} / \mathrm{L}$ (Table 3 and Fig. 4), which are comparable with some reports (Mouatassim-Souali et al., 2003; Ying et al., 2002), but higher than those from Germany (Adler et al., 2001). $E_{3}$ was detected only in one of the ten samples (39 ng/L, LOD $5.9 \mathrm{ng} / \mathrm{L}$ ). Some investigations stated that $\mathrm{E}_{3}$ had disappeared after wastewater treatment (Quintana et al., 2004; Sole et al., 2000); conversely, Johnson and Sumpter (2001) reported a typical effluent concentration of $E_{3}$ was $20 \mathrm{ng} / \mathrm{L}$, which was the highest among the four chemicals. 

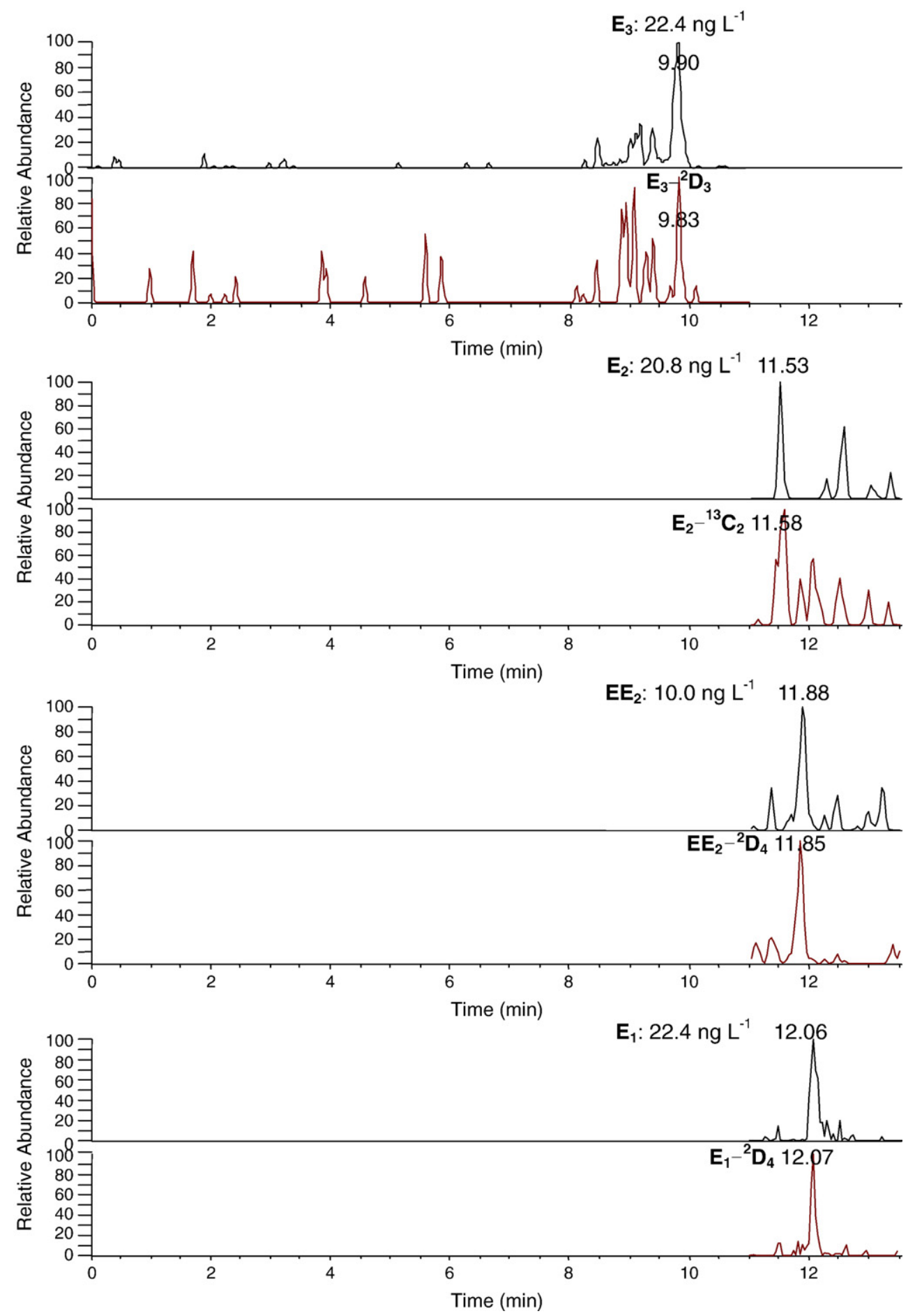

Fig. 3. The chromatogram of a river water sample (SRM Mode).

\subsubsection{Matrix effects}

Significant matrix effects were seen on real samples, and were more prominent in the river water samples. Use of isotope-dilution techniques is the best way to tackle the effects (Van De Steene et al., 2006). LODs of real samples were much higher and their IS recoveries were lower (Table 3) than those of Milli-Q water. Higher background noises, ion suppression or breakthrough on 

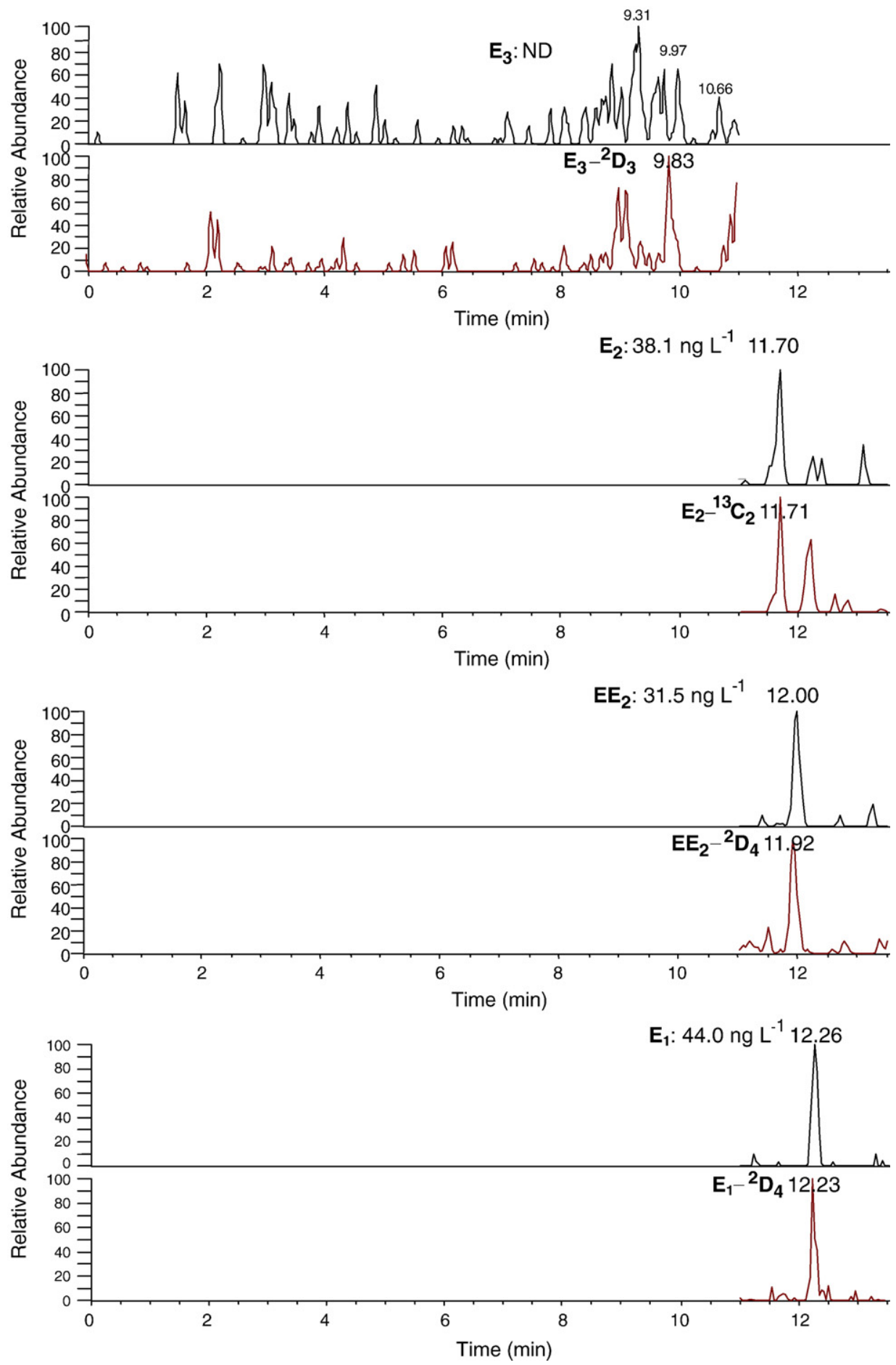

Fig. 4. The chromatogram of a WWTP effluent water sample (SRM Mode).

the disks could be the cause of this. To evaluate the matrix effect, we re-injected river water and effluent final extracts and their $10 \times$ dilutions. For $\mathrm{E}_{1}, \mathrm{E}_{2}$, and
$\mathrm{EE}_{2}$, recoveries of the diluted river water and effluent extracts were 2.3-3.7 and 1.5-2.5 times higher (mean, $n=4$ ) than those of original ones, respectively. The 
differences in recoveries were more apparent for $\mathrm{E}_{3}(7.1$ and 5.0-fold, respectively), which could be explained by its earlier elution on HPLC.

The organic matter and other chemicals present in matrixes could compete for binding sites and reduce the capacity of the disks, resulting in a breakthrough of analytes (Xiao et al., 2001) and lower recoveries. Because the breakthrough tests were done using Milli-Q water, this factor cannot be excluded. To determine the possible effects of ion suppression and disk overloading, we spiked $50 \mathrm{ng}$ of the four analytes into 1-L filtered raw water from Sin-Dian Creek before (set A, $n=4$ ) and after the extraction (set $\mathrm{B}, n=4$ ). The raw water samples contained $<2 \mathrm{ng} / \mathrm{L}$ of the analytes, with levels insignificant compared with the spiked amount. The recoveries of $\mathrm{E}_{1}$, $\mathrm{E}_{2}, \mathrm{EE}_{2}$, and $\mathrm{E}_{3}$ in set $\mathrm{B}$ were $89.8 \pm 11.6 \%, 95.5 \pm 9.3 \%$, $67.7 \pm 10.2 \%$ and $66.6 \pm 9.2 \%$, respectively, calculated using the analyte standards (external calibration). We found ion suppression to be considerable in $\mathrm{EE}_{2}$ and $\mathrm{E}_{3}$. The recoveries of $\mathrm{E}_{1}, \mathrm{E}_{2}, \mathrm{EE}_{2}$, and $\mathrm{E}_{3}$ in set A were $41.9 \pm$ $6.4 \%, 38.9 \pm 5.6 \%, 56.0 \pm 4.5 \%$ and $39.3 \pm 2.7 \%$, respectively, calculated using the recoveries of set $\mathrm{B}$. The data cancelled out the ion suppression effect and revealed the influence of matrix to extraction efficiency. Compared with the recoveries in Milli-Q water, the matrix notably reduced the extraction efficiencies of $E_{1}, E_{2}$, and $E_{3}$, though the impact was less on $\mathrm{EE}_{2}$, possibly because of its hydrophobicity; consequently, it would be better to use less sample volume in future studies. We demonstrated that disk overloading also influenced recoveries in addition to ion suppression for the raw water from SinDian Creek, which is used as a drinking water source. However, the relative impact of these two factors on recoveries may not be the same in the Dan-Shui River water and WWTP effluents because of their inferior water quality, which, due to the high concentrations of the analytes, were not suitable for this evaluation.

\subsubsection{Effects of pre-filtration of samples}

Removal of particulates before extraction caused an underestimation of total concentrations of $E_{1}$ and $E_{2}$ in river water and WWTP effluents, and the effects were stronger in river water. To avoid the clog of the adsorbent with particulates in water, there is a filtration step before SPE; therefore, existing methods actually extract soluble estrogenic steroids. To clarify the issue of particulate adsorption, we separated the river and WWTP effluent samples into two batches: one spiked with the isotope-labeled IS ( $20 \mathrm{ng} / \mathrm{L})$ before filtering the particles and the other spiked after the filtration. In both matrixes, there were no significant differences in IS recoveries of $\mathrm{E}_{2}$ and $\mathrm{E}_{3}(p=0.16-0.43, n=10)$ regard- less of when IS was added. Furhacker et al. (1999) reported that $\mathrm{E}_{2}$ in wastewater at $\mathrm{ng} / \mathrm{L}$ levels mainly remains in the aqueous phase, which is consistent with our findings. In contrast, the IS recoveries of $\mathrm{E}_{1}$ and $\mathrm{EE}_{2}$ spiked after filtration were significantly higher in both the river water ( $3-4$ times higher, $p \ll 0.01, n=10)$ and WWTP effluents (1.6- to 1.9-fold higher, $p<0.01$, $n=10)$. The water solubilities of $\mathrm{E}_{1}, \mathrm{E}_{2}$, and $\mathrm{E}_{3}$ are around $13 \mathrm{mg} / \mathrm{L}$, and that of $\mathrm{EE}_{2}$ is only $4.8 \mathrm{mg} / \mathrm{L}$ (Xiao et al., 2001; Ying et al., 2002); the $\log K_{\text {ow }}$ of $\mathrm{E}_{3}, \mathrm{E}_{2}, \mathrm{E}_{1}$, and $\mathrm{EE}_{2}$ are 2.5-2.8, 3.1-4.0, 3.1-3.4, and 3.7-4.2, respectively (Westerhoff et al., 2005; Ying et al., 2002). The relative hydrophobicity of $\mathrm{EE}_{2}$ would explain its higher influence by particulate binding. Although the observed difference of particulate binding effect on $E_{1}$ and $\mathrm{E}_{2}$ could not be explained based on their water solubility and $\log K_{\text {ow }}$, the replacement of the hydroxyl group on the 17 th carbon of $E_{2}$ with a ketone on $E_{1}$ may reduce the polarity of $E_{1}$ and increase the binding. Moreover, the total suspended solids in the river water $(56-73 \mathrm{mg} / \mathrm{L})$ were higher than those in the effluents (18-27 mg/L), possibly explaining the stronger effects of particulate binding in river water.

\subsection{Removal of steroid estrogens from drinking water treatment}

\subsubsection{Chlorination}

Normal chlorination processing in drinking water treatment may degrade estrogens inefficiently. Our results showed that only $20-40 \%$ of estrogenic steroids were eliminated by chlorination (Table 4). The matrix for postchlorination contained considerably fewer particulates and organics after the pre-treatment of pre-chlorination, coagulation/sedimentation and rapid filtration. However, no significant differences in removal rates were observed between pre-chlorination and post-chlorination. One Japanese study (Snyder et al., 2003) also reported on the ineffectiveness of chlorination. Our tested concentrations of analytes did not significantly impact the removal rates except for $\mathrm{E}_{2}$ in pre-chlorination and $\mathrm{EE}_{2}$ in postchlorination. There was no significant difference in the percentage removed among individual analytes, except for $E_{2}$, which was degraded more than $E_{3}$ at $500 \mathrm{ng} / \mathrm{L}$ in pre-chlorination ( $p=0.03$ ).

Some studies have demonstrated rapid or complete consumption of estrogenic steroids by chlorination; however, these studies were done with Milli-Q water or buffer solutions (Hu et al., 2003; Moriyama et al., 2004), used increased doses of total chlorine (Deborde et al., 2004), elongated contact time (Westerhoff et al., 2005) or utilized much higher initial concentrations of analytes 
Table 4

Percentage removal in drinking water treatment processes (mean $\pm \mathrm{SD}, n=4)$

\begin{tabular}{llllll}
\hline Process & Initial concentration $(\mathrm{ng} / \mathrm{L})$ & Estrone $\left(\mathrm{E}_{1}\right)$ & $17 \beta$-estradiol $\left(\mathrm{E}_{2}\right)$ & $17 \alpha$-ethinyl estradiol $\left(\mathrm{EE}_{2}\right)$ & $\mathrm{Estriol}_{\left(\mathrm{E}_{3}\right)}$ \\
\hline Pre-chlorination & 100 & $33.4 \pm 9.2$ & $19.1 \pm 16.5^{\mathrm{a}}$ & $23.7 \pm 5.1$ & $28.0 \pm 7.0$ \\
& 500 & $34.8 \pm 5.6$ & $39.5 \pm 4.8^{\mathrm{b}}$ & $28.3 \pm 10.7$ & $23.2 \pm 6.0$ \\
Coagulation/sedimentation & 100 & $37.3 \pm 14.9$ & $52.1 \pm 4.1^{\mathrm{a}, \mathrm{c}}$ & $17.3 \pm 15.3$ & $26.7 \pm 9.2$ \\
& 500 & $29.8 \pm 3.0$ & $35.7 \pm 10.8$ & $27.1 \pm 7.9$ & $20.0 \pm 7.5$ \\
Rapid filtration & 100 & $94.1 \pm 5.6$ & $96.3 \pm 5.5$ & $94.9 \pm 5.4$ & $92.4 \pm 4.1$ \\
& 500 & $98.1 \pm 2.2^{\mathrm{b}}$ & $98.7 \pm 1.0^{\mathrm{b}}$ & $98.4 \pm 1.7^{\mathrm{b}}$ & $83.6 \pm 7.6$ \\
Post- chlorination & 100 & $27.7 \pm 17.2$ & $22.4 \pm 14.4$ & $44.0 \pm 5.8^{\mathrm{a}}$ & $31.5 \pm 4.8$ \\
& 500 & $25.3 \pm 10.1$ & $35.9 \pm 12.9$ & $16.7 \pm 10.2$ & $22.3 \pm 8.4$ \\
Whole process & 100 & $94.2 \pm 4.8^{\mathrm{b}}$ & $88.4 \pm 10.1$ & $92.9 \pm 4.3$ & $84.7 \pm 6.3^{\mathrm{a}}$ \\
& 500 & $90.5 \pm 6.7^{\mathrm{b}}$ & $89.3 \pm 3.6^{\mathrm{b}}$ & $93.3 \pm 1.7^{\mathrm{b}}$ \\
\hline
\end{tabular}

Significantly different with the removal percentage of the $500 \mathrm{ng} / \mathrm{L}$.

Significantly higher than $\mathrm{E}_{3}$.

Significantly higher than $\mathrm{EE}_{2}$.

(Carlile et al., 1996) irrelevant to environmental levels. The enhanced removal can be explained by a lack of competing organics or by the second-order reaction of $\mathrm{HOCl}$ with phenolic steroid estrogens (Deborde et al., 2004), though formation of more disinfection byproducts may cause another concern.

\subsubsection{Coagulation and sedimentation}

Alum coagulation mainly removes chemicals adsorbing to particulates. This process eliminated $20-50 \%$ of the four analytes in our study (Table 4). There were no significant differences in percentage removed among the four analytes despite their different $\log K_{\mathrm{ow}}$, with the exception of $E_{2}$ which was precipitated significantly more than $\mathrm{EE}_{2}$ at $100 \mathrm{ng} / \mathrm{L}(p=0.028)$, which conflicted with its hydrophobicity. Our results are consistent with previous investigations that show only relatively high$K_{\text {ow }}$ chemicals (e.g. $>10^{5}$ ) can be removed appreciably during coagulation (Snyder et al., 2003; Westerhoff et al., 2005).

The tested initial concentrations did not perceptibly affect the removal rates except that more $E_{2}$ was removed at $100 \mathrm{ng} / \mathrm{L}$ than that of $500 \mathrm{ng} / \mathrm{L}(p=0.024)$; Westerhoff and colleagues (2005) also indicated that spiked concentration did not change the removal percentage at $10-250 \mathrm{ng} / \mathrm{L}$.

We found that filtering out particulates before SPE may reduce some $E_{1}$ and $E_{2}$ in river water and WWTP effluents, but not in the drinking water. The low turbidity of our raw water (3.6-7.7 NTU) would explain the difference. To further clarify the issue, we treated raw water spiked at $100 \mathrm{ng} / \mathrm{L}$ with $50-\mathrm{mg} / \mathrm{L}$ alum and found an average removal percentage of $31-38 \%(n=3$, SD 3.6-7.8\%), showing no significant increase compared with that of $5-\mathrm{mg} / \mathrm{L}$ alum.

\subsubsection{Rapid filtration}

The rapid filtration process removed most estrogenic steroids and performed significantly better than all other steps $(p<0.001) .92-98 \%$ of the analytes were eliminated excluding a lower removal of $E_{3}$ than other analytes at $500 \mathrm{ng} / \mathrm{L}(84 \%, p=0.001)$ (Table 4). The spiked concentration did not notably affect the removal percentage.

The removal was unexpectedly high if the filtration process only removed particulates and adhering chemicals. To elucidate the removal mechanism, we packed two types of columns for further investigations: in addition to $30-\mathrm{cm}$ of filter gravel for support in both, one was packed with $76-\mathrm{cm}$ crushed anthracite and the other with $76-\mathrm{cm}$ of filter sand. For the columns packed with the anthracite, the average removal percentage at $100 \mathrm{ng} / \mathrm{L}$ was $97-98 \%$ $(n=4$, SD 1.9-2.6\%), which was similar to that of the original packed filtration columns. The columns packed with filter sand eliminated $34-46 \%$ of the analytes $(n=4$, SD 5.4-6.3\%). Milli-Q water spiked at $100 \mathrm{ng} / \mathrm{L}$ were also treated with the columns packed with filter sand and had a removal percentage consistent with that of raw water $(n=4$, mean $31-42 \%$, SD 5.2-10\%). Consequently, the primary mechanism behind the removal was the adsorption of the organics by the anthracite rather than the filtering out of analytes adhering to particulates. Powdered activated carbon has been shown to be a good adsorbent for estrogenic compounds in advanced treatment (Snyder et al., 2003; Westerhoff et al., 2005), and it is interesting to find that crushed anthracite in conventional rapid filtration gave a comparable performance. Surprisingly, filter sand itself removed over $30 \%$ of the analytes not only from the raw water treated through prechlorination and coagulation but also from the Milli-Q water, which contained almost no particulates. 


\subsubsection{The whole process}

The whole treatment eliminated $88-94 \%$ of $E_{1}, E_{2}$, and $\mathrm{EE}_{2}$ and the spiked levels did not apparently influence their removal percentage (Table 4); the removal rate of $\mathrm{E}_{3}$ was similar at $100 \mathrm{ng} / \mathrm{L}(84.7 \pm$ $6.3 \%$ ) but was significantly lower than other analytes at $500 \mathrm{ng} / \mathrm{L}(64.4 \pm 2.9 \%)$.

Changes in concentrations after one treatment would have some minor effect on the removal of the next unit. Based on the removal percentage of each unit, the four analytes should be almost completely removed after the whole procedure. We did not observe apparent effects of the initial spiked levels to the performance in a single unit for most analytes; however, the combination of the four steps could not remove all estrogens at our study concentrations. A possible explanation for this observation is because of the lower concentrations of estrogens in the filtration unit. Wang (1994) demonstrated that lower initial atrazine concentrations lead to lower adsorption capacity in activated carbon because of the competition of natural organic matter in the water. When the spiked estrogens went through the prechlorination and coagulation/sedimentation units, their concentrations would have decreased $30-50 \%$ and resulted in a lower adsorption onto the anthracite. However, further studies are necessary to elucidate this phenomenon.

No estrogenic steroids were detected in the treated water from Chang-Hsing WTP $(n=6$, LOD $0.06-$ $0.15 \mathrm{ng} / \mathrm{L}$ ). The concentrations of the four analytes in the raw water were ND-5.9 ng/L, which were much lower than those in Dan-Shui River. In the detectable water samples, the average concentrations were 1.6$2.4 \mathrm{ng} / \mathrm{L}$. Consequently, a conventional drinking water treatment should be able to handle the low concentrations of estrogenic steroids in the water source. While investigations report the absence of estrogenic steroids after conventional treatment (Fawell et al., 2001; Rodriguez-Mozaz et al., 2004), this may be because most drinking water sources are cleaner than usual surface water. A conventional drinking water treatment cannot guarantee complete removal of the analytes in re-used water in which initial concentrations are higher.

\section{Conclusion}

Our study demonstrates that PolarPlus C18 adsorbent can effectively be used to extract steroid estrogens from a large volume of water under a high-flow rate with no need to acidify samples. This saves a lot of time and labor. However, extracting less volume of water is suggested for dirty samples to alleviate the matrix effects and breakthrough. Our data indicates that prefiltration before SPE to avoid the clog of the adsorbent might significantly influence the estimation of total $E_{1}$ and $\mathrm{EE}_{2}$ in river water and WWTP effluents; therefore, isotope-labeled IS should be spiked before rather than after the filtration step to correct for the loss of analytes due to partitioning to particulates. The use of isotopelabeled IS would also compensate the variations of SPE efficiencies caused by matrixes; extensive cleanup will decrease ion suppression but will not reduce the competition for adsorbent binding sites from soluble organics present in water.

Rapid filtration gave the best removal percentage (over 84\%); the chlorination processes did not perform as well in our study as other reports (Snyder et al., 2003). While a conventional WTP should be able to eliminate trace levels of estrogenic steroids, we observed incomplete removal at higher concentrations, especially for the more hydrophilic $E_{3}$. Advanced treatment will be needed if reclaimed water is directly used for drinking water.

\section{Acknowledgements}

Assistance of water sampling was from Technical Laboratory of Taipei Department of Environmental Protection, Taipei Water Department and Sewage Systems Office of Taipei City Government. This work was funded by the National Science Council, Taiwan. The LC-MS/MS was kindly offered by the College of Medicine, National Taiwan University.

\section{References}

Adler P, Steger-Hartmann T, Kalbfus W. Distribution of natural and synthetic estrogenic steroid hormones in water samples from southern and middle Germany. Acta Hydrochim Hydrobiol 2001;29:227-41.

Adlercreutz H, Gorbach SL, Goldin BR, Woods MN, Dwyer JT, Hamalainen E. Estrogen metabolism and excretion in oriental and Caucasian women. J Natl Cancer Inst 1994;86:1076-82.

Alum A, Yoon Y, Westerhoff P, Abbaszadegan M. Oxidation of bisphenol A, 17 beta-estradiol, and 17 alpha-ethynyl estradiol and byproduct estrogenicity. Environ Toxicol 2004;19:257-64.

Arcand-Hoy LD, Nimrod AC, Benson WH. Endocrine-modulating substances in the environment: estrogenic effects of pharmaceutical products. Int J Toxicol 1998;17:139-58.

Baronti C, Curini R, D’Ascenzo G, Di Corcia A, Gentili A, Samperi R. Monitoring natural and synthetic estrogens at activated sludge sewage treatment plants and in a receiving river water. Environ Sci Technol 2000;34:5059-66.

Benijts T, Lambert W, De Leenheer A. Analysis of multiple endocrine disruptors in environmental waters via wide-spectrum solid-phase extraction and dual-polarity ionization LC-ion trap-MS/MS. Anal Chem 2004;76:704-11. 
Carlile P, Fielding M, Harding L, Hart J, Hutchison J, Kanda R. Effect of water treatment processes on oestrogenic chemicals. 96/DW/05/ 10. London: UK Water Industry Research; 1996. http://www. ukwir.org/, access date Aug. 2006.

Carpinteiro J, Quintana JB, Rodriguez I, Carro AM, Lorenzo RA, Cela R. Applicability of solid-phase microextraction followed by onfiber silylation for the determination of estrogens in water samples by gas chromatography-tandem mass spectrometry. J Chromatogr A $2004 ; 1056: 179-85$

Chen C-Y, O'Keefe PW, Aldous KM. Analysis of 11 Pharmaceuticals by High Performance Liquid Chromatography/Mass Spectrometry. The Society of Environmental Toxicology and Chemistry (SETAC) 22nd annual meeting, November; 2001. Baltimore, Maryland, USA.

Deborde M, Rabouan S, Gallard H, Legube B. Aqueous chlorination kinetics of some endocrine disruptors. Environ Sci Technol 2004;38:5577-83.

Desbrow C, Routledge EJ, Brighty GC, Sumpter JP, Waldock M. Identification of estrogenic chemicals in STW effluent. 1. Chemical fractionation and in vitro biological screening. Environ Sci Technol 1998;32:1549-58.

Ericson JF, Laenge R, Sullivan DE. Comment on "Pharmaceuticals, hormones, and other organic wastewater contaminants in US streams, 1999-2000: a national reconnaissance". Environ Sci Technol 2002;36:4005-6.

Fawell JK, Sheahan D, James HA, Hurst M, Scott S. Oestrogens and oestrogenic activity in raw and treated water in Severn Trent Water. Water Res 2001;35:1240-4.

Fine DD, Breidenbach GP, Price TL, Hutchins SR. Quantitation of estrogens in ground water and swine lagoon samples using solidphase extraction, pentafluorobenzyl/trimethylsilyl derivatizations and gas chromatography-negative ion chemical ionization tandem mass spectrometry. J Chromatogr A 2003;1017:167-85.

Furhacker M, Breithofer A, Jungbauer A. 17 beta-estradiol: behavior during waste water analyses. Chemosphere 1999;39:1903-9.

Hu JY, Cheng SJ, Aizawa T, Terao Y, Kunikane S. Products of aqueous chlorination of 17 beta-estradiol and their estrogenic activities. Environ Sci Technol 2003;37:5665-70.

Isobe T, Shiraishi H, Yasuda M, Shinoda A, Suzuki H, Morita M. Determination of estrogens and their conjugates in water using solid-phase extraction followed by liquid chromatography-tandem mass spectrometry. J Chromatogr A 2003;984:195-202.

Itoh S, Ueda H, Naasaka T, Nakanishi G, Sumitomo H. Evaluating variation of estrogenic effect by drinking water chlorination with the MVLN assay. Water Sci Technol 2000;42:61-9.

Jobling S, Nolan M, Tyler CR, Brighty G, Sumpter JP. Widespread sexual disruption in wild fish. Environ Sci Technol 1998;32:2498-506.

Johnson AC, Sumpter JP. Removal of endocrine-disrupting chemicals in activated sludge treatment works. Environ Sci Technol 2001;35:4697-703.

Johnson AC, Belfroid A, Di Corcia A. Estimating steroid oestrogen inputs into activated sludge treatment works and observations on their removal from the effluent. Sci Total Environ 2000;256:163-73.

Jurgens MD, Williams RJ, Johnson AC. Fate and behaviour of steroid oestrogens in rivers- a scoping study. R\&D Technical Report P161. Swindon, Wilts: U.K. Environment Agency; 1999. http:// publications.environment-agency.gov.uk/pdf/STRP161-e-p.pdf, access date Aug 2006.

Kolodziej EP, Harter T, Sedlak DL. Dairy wastewater, aquaculture, and spawning fish as sources of steroid hormones in the aquatic environment. Environ Sci Technol 2004;38:6377-84.

Kolpin DW, Furlong ET, Meyer MT, Thurman EM, Zaugg SD, Barber $\mathrm{LB}$, et al. Pharmaceuticals, hormones, and other organic wastewater contaminants in US streams, 1999-2000: a national reconnaissance. Environ Sci Technol 2002a;36:1202-11.

Kolpin DW, Furlong ET, Meyer MT, Thurman EM, Zaugg SD, Barber LB, et al. Response to comment on "Pharmaceuticals, hormones, and other organic wastewater contaminants in US streams, 1999-2000: a national reconnaissance". Environ Sci Technol 2002b;36:4007-8.

Lee BC, Kamata M, Akatsuka Y, Takeda M, Ohno K, Kamei T, et al. Effects of chlorine on the decrease of estrogenic chemicals. Water Res 2004;38:733-9.

Moriyama K, Matsufuji H, Chino M, Takeda M. Identification and behavior of reaction products formed by chlorination of ethynylestradiol. Chemosphere 2004;55:839-47.

Mouatassim-Souali A, Tamisier-Karolak SL, Perdiz D, Cargouet M, Levi Y. Validation of a quantitative assay using GC/MS for trace determination of free and conjugated estrogens in environmental water samples. J Sep Sci 2003;26:105-11.

Petrovic M, Barcelo D. The stability of non-ionic surfactants and linear alkylbenzene sulfonates in a water matrix and on solid-phase extraction cartridges. Fresenius J Anal Chem 2000;368:676-83.

Quintana JB, Carpinteiro J, Rodriguez I, Lorenzo RA, Carro AM, Cela R. Determination of natural and synthetic estrogens in water by gas chromatography with mass spectrometric detection. J Chromatogr A 2004;1024:177-85.

Rodriguez-Mozaz S, de Alda MJL, Barcelo D. Monitoring of estrogens, pesticides and bisphenol $\mathrm{A}$ in natural waters and drinking water treatment plants by solid-phase extraction-liquid chromatographymass spectrometry. J Chromatogr A 2004;1045:85-92.

Snyder SA, Westerhoff P, Yoon Y, Sedlak DL. Pharmaceuticals, personal care products, and endocrine disruptors in water: implications for the water industry. Environ Eng Sci 2003;20:449-69.

Sole M, de Alda MJL, Castillo M, Porte C, Ladegaard-Pedersen K, Barcelo D. Estrogenicity determination in sewage treatment plants and surface waters from the Catalonian area (NE Spain). Environ Sci Technol 2000;34:5076-83.

Spengler P, Korner W, Metzger JW. Substances with estrogenic activity in effluents of sewage treatment plants in southwestern Germany. 1. Chemical analysis. Toxicol Chem 2001;20:2133-41.

Taiwan EPA (Environmental Protection Administration). Environmental protection data in Taiwan. Taiwan: Environmental Protection Administration, Executive Yuan; 2006. http://edb.epa. gov.tw/Index_water.htm, access date Aug. 2006.

TDEP (Taipei Department of Environmental Protection). River water quality. Taipei, Taiwan: Technical Laboratory, Department of Environmental Protection; 2004. http://211.79.130.66/c_index/ envir/water_r_1.asp, access date Aug. 2006.

Ternes TA, Kreckel P, Mueller J. Behaviour and occurrence of estrogens in municipal sewage treatment plants - ii. Aerobic batch experiments with activated sludge. Sci Total Environ 1999;225:91-9.

Van De Steene JC, Mortier KA, Lambert WE. Tackling matrix effects during development of a liquid chromatographic-electrospray ionisation tandem mass spectrometric analysis of nine basic pharmaceuticals in aqueous environmental samples. J Chromatogr A 2006;1123:71-81.

Vanderford BJ, Pearson RA, Rexing DJ, Snyder SA. Analysis of endocrine disruptors, pharmaceuticals, and personal care products in water using liquid chromatography/tandem mass spectrometry. Anal Chem 2003;75:6265-74.

Vethaak AD, Lahr J, Schrap SM, Belfroid AC, Rijs GBJ, Gerritsen A, et al. An integrated assessment of estrogenic contamination and biological effects in the aquatic environment of The Netherlands. Chemosphere 2005;59:511-24.

Wang G-S. Removal of atrazine from drinking water by activated carbon adsorption. $\mathrm{PhD}$ dissertation in the Department of 
Environmental Health Sciences. Albany, NY: State University of New York at Albany; 1994.

Westerhoff P, Yoon Y, Snyder S, Wert E. Fate of endocrine-disruptor, pharmaceutical, and personal care product chemicals during simulated drinking water treatment processes. Environ Sci Technol 2005;39:6649-63.

Xiao XY, McCalley DV, McEvoy J. Analysis of estrogens in river water and effluents using solid-phase extraction and gas chromatography- negative chemical ionisation mass spectrometry of the pentafluorobenzoyl derivatives. J Chromatogr A 2001;923:195-204.

Ying GG, Kookana RS, Ru YJ. Occurrence and fate of hormone steroids in the environment. Environ Int 2002;28:545-51.

Zwiener C, Richardson SD. Analysis of disinfection by-products in drinking water by LC-MS and related MS techniques. Trends Anal Chem 2005;24:613-21. 